\title{
O DEBATE CONCEITUAL SOBRE TERCEIRIZAÇÃO: uma abordagem interdisciplinar
}

\author{
Isabela Fadul de Oliveira * *
}

Graça Druck*

\begin{abstract}
O artigo tem por objetivo sistematizar e problematizar o conceito de terceirização nas pesquisas brasileiras, buscando tecer um diálogo entre as diferentes áreas disciplinares de estudos, bem como indicar os diferentes níveis de abstração do conceito. Parte-se de uma definição mais ampla e estrutural do lugar da terceirização no capitalismo contemporâneo, discutindo as diferentes formas de terceirização, reveladas pelos estudos empíricos, para, a partir deles, apresentar alguns conceitos operacionais, especialmente no campo jurídico. Para além da problematização conceitual, apresenta-se uma proposta para criar uma metodologia qualitativa de construção de indicadores que permitam dimensionar a terceirização, tomando como “dados brutos" os resultados de pesquisas empíricas desenvolvidas no país.
\end{abstract}

PALAVRAS-CHAVES: Terceirização. Conceito. Indicadores.

\section{INTRODUÇÃO}

$\mathrm{O}$ artigo tem por objetivo sistematizar e problematizar o conceito de terceirização nas pesquisas brasileiras, buscando tecer um diálogo entre as diferentes áreas disciplinares de estudos, bem como indicar os diferentes níveis de abstração conceitual.

Parte-se de uma definição mais ampla e estrutural do lugar da terceirização no capitalismo contemporâneo, discutindo as diferentes formas de terceirização, reveladas pelos estudos empíricos, para com base neles, apresentar alguns conceitos operacionais, que auxiliem nas análises comparativas do fenômeno nas diversas realidades nacionais.

Defende-se a tese de que a terceirização é um fenômeno de natureza multidisciplinar e que tem sido analisado por várias áreas do

* Universidade Federal da Bahia. Faculdade de Filosofia e Ciências Humanas.

Estrada de São Lázaro, 197 - Federação. Cep: 40210-909. Salvador - Bahia - Brasil. druckg@gmail.com. https://orcid.org/0000-0003-0363-6883

** Universidade Federal da Bahia. Faculdade de Direito. Departamento de Direito Privado.

Rua da Paz, s/n, Graça, CEP 40231-300, Salvador, Bahia, Brasil.isabelafadul@gmail.com

https://orcid.org/0000-0002-4825-2819 conhecimento acadêmico, com destaque pela sociologia, economia e direito, cujas abordagens permitem identificar os diferentes campos ou "lugares" nos quais a terceirização se manifesta, mostrando que ela é também multidimensional, isto é, pode ser analisada no âmbito do processo de trabalho, do mercado de trabalho, dos direitos do trabalho, da regulação do trabalho, da organização coletiva e da saúde do trabalhador.

Para além da problematização conceitual, apresenta-se uma proposta de criação de uma metodologia qualitativa de construção de indicadores que permitam dimensionar a terceirização, tomando como "dados brutos", os resultados de pesquisas empíricas desenvolvidas no país.

O artigo está composto por quatro seções, além dessa introdução e das conclusões finais. Na primeira, recupera-se a origem histórica da terceirização e descreve-se suas feições no capitalismo contemporâneo, especialmente as formas que assume em economias dependentes, como a brasileira. Em seguida, discute-se a existência e a importância de um conceito operacional que embase as pesquisas 
que tomam o fenômeno da terceirização como objeto de estudo nas diversas áreas das ciências sociais. Na última parte do texto, defende-se a necessidade da construção de uma metodologia qualitativa e complementar de análise da terceirização, com base na construção em rede de uma base de dados e de indicadores de terceirização, que permitam dimensionar e avaliar o fenômeno em perspectiva comparada.

\section{A ORIGEM HISTÓRICA E ATUAL DA TERCEIRIZAÇÃO NO CAPITA- LISMO CONTEMPORÂNEO}

A terceirização tem sua origem nos primórdios do capitalismo industrial. Segundo Braverman (1987), nessa etapa inicial da industrialização havia um esforço do capitalista para negar a diferença entre força de trabalho e o trabalho que se obtém dela, buscando comprá-la da mesma forma que comprava as matérias primas, na tentativa de "esquivar-se da gerência”. A forma como assumia essa postura do capitalista era o "sistema de subcontratação", através do trabalho domiciliar no setor têxtil, de metal, de couros, relojoaria, dentre outros, que era subcontratado por "agentes em comissão". Mas até mesmo nas minas, haviam trabalhadores contratados por um "empregador subcontratador" que intermediava a relação de trabalho. Tal processo permaneceu até సิ o final do século XIX. Ainda segundo Braverণ के man, esses sistemas de subcontratação foram ํ. parte de um momento de transição, quando o ชิ capitalista ainda não havia assumido a direção $\stackrel{\text { จิ }}{\rightarrow}$ e o controle sobre o processo de trabalho e, “... ¿. por esta razão era incompatível com o desenलिं volvimento geral da produção capitalista, e $\vec{s}$ sobrevive apenas em casos especiais" (Braverman, 1987, p.64). Uma análise que tem o intuito de demonstrar a necessidade da "gerência" e, portanto, do controle do capitalista sobre o processo de trabalho. Na visão de Braverman, o sistema de subcontratação daquela época impedia esse controle, dificultava a produtivida- de e era um empecilho ao desenvolvimento do processo capitalista de produção.

Segundo Castel (1998), antes mesmo do capitalismo industrial, no séc. XVI na Inglaterra e na França, havia a disputa pelo controle do mercado e do trabalho entre os mercadores, especialmente os mercadores-empregadores que pressionavam os artesãos independentes para se submeterem à "lógica de subcontratação", que tinha como objetivo a subordinação e proletarização de um segmento dos artesãos, levando à perda de sua independência e de seus direitos de propriedade sobre a produção e sobre o trabalho.

Castel (1998) se refere também à origem do "putting-out-system", através do artesanato rural, que ocupou um lugar importante no processo de acumulação nesse período. As vantagens destacadas à época não são muito diferentes da atualidade: salários mais baixos do que o dos artesãos urbanos e uma flexibilidade produtiva, com menor investimento em capital fixo, já que o trabalho era realizado nos domicílios dos artesãos rurais. Além disso, o recurso ao artesanato rural mantinha o homem no campo, restringindo o êxodo e preservando a tutela dos mercadores urbanos. Condição que contribuiu para o retardo da formação do proletariado moderno e da concentração do trabalho industrial nas cidades.

No caso do Brasil, o velho fenômeno da terceirização tem sua origem no trabalho rural, através do sistema de "gato", que é a intermediação para a contratação de trabalhadores para o trabalho tipicamente sazonal (intermitente) e que permanece na agricultura até os dias atuais, como explica Carvalho (2015). Ao tratar do fenômeno da terceirização no campo e seu impacto no enfraquecimento dos controles justrabalhistas nas relações de emprego, o autor afirma:

A terceirização de mão de obra se perfaz através da presença de uma figura intermediária entre os sujeitos da relação de emprego. Nas atividades rurais, esse intermediário é comumente conhecido como gato ou turmeiro e acumula as funções de contra- 
tante da mão de obra e fiscal do trabalho. Conhecendo as demandas dos empreendimentos rurais, o gato alicia os trabalhadores, geralmente pessoas oriundas de regiões diversas ao local de prestação do serviço, em situação de vulnerabilidade social e econômica, para inseri-los em atividades pontuais do ciclo produtivo agrícola. As empresas rurais remuneram diretamente o intermediador que posteriormente faz a contratação dos empregados (Carvalho, 2015, p.113).

O seu nascedouro remonta ao século XIX, mais precisamente a 1852, no processo de substituição do trabalho escravo pelo trabalho dos migrantes pobres europeus, quando surgiram agenciadoras privadas de mão de obra estrangeira para as grandes plantações, subcontratadas pelo governo e impondo condições de súperexploração do trabalho dos migrantes, que, imobilizados nas fazendas, levou à chamada "escravidão branca" ou "parceria por endividamento” (Kowarick, 1994; Viotti da Costa, 1977).

A partir dessas referências à origem histórica da terceirização, é necessário perguntar qual é o lugar e no que se transformou a terceirização no capitalismo contemporâneo. Considera-se a terceirização um fenômeno velho e novo. Velho porque se caracteriza como uma prática utilizada desde a revolução industrial (para permanecer nos marcos do capitalismo moderno), que continua no séc. XX, durante o auge do fordismo e dos estados de bem-estar-social, na Europa e EUA e no processo de industrialização no Brasil, embora ocupando um lugar periférico nas formas de organização do trabalho capitalista, notadamente nos centros urbanos industriais.

$\mathrm{Na}$ atual era do capitalismo flexível, a terceirização caracteriza-se como um fenômeno novo, porque passa a ocupar um lugar central nas chamadas novas formas de gestão e organização do trabalho, inspiradas no "modelo japonês" (toyotismo), implementadas no bojo da reestruturação produtiva, como resposta à crise do fordismo em âmbito mundial, desde as duas últimas décadas do século passado.

O caráter de novo fenômeno é dado pela amplitude, pela natureza e pela centralidade que assume neste novo momento do capitalismo mundializado ou da "acumulação flexível" (Harvey, 1992). Trata-se de um processo de metamorfose, já que a terceirização deixa de ser utilizada de forma marginal ou periférica para se tornar o centro das novas formas de organização do trabalho, como parte essencial da estrutura produtiva no capitalismo flexível e globalizado. (Araújo, 2001; Thebaud-Mony e Druck, 2007, Filgueiras e Cavalcante, 2015). É hoje um fenômeno mundial que se generalizou para todas as atividades urbanas e rurais; na indústria, comércio, serviços e setores público e privado, apresentando diferentes modalidades e formas de regulação.

A especificidade histórica do processo de trabalho capitalista, na perspectiva marxiana, é a de produzir mais valor, cujas formas de produção vão se alterando no processo de desenvolvimento do capitalismo. Da cooperação, manufatura e grande indústria, conforme explicados por Marx em O Capital, as formas de organização do trabalho para produzir mais valor vão se transformando, fruto das disputas entre capital e trabalho e da permanente necessidade de controle e disciplinamento do trabalho pelo capital.

É a partir dessa natureza histórica do processo de trabalho, que se pode compreender os diferentes padrões de organização do trabalho, como o taylorismo, o fordismo e o toyotismo, todos eles reveladores de determinadas condições socioeconômicas e políticas, advindas da resistência dos trabalhadores às formas de controle e, consequentemente, da elaboração de novas estratégias de dominação do capital no plano da organização e regulação do trabalho.

Nessa perspectiva, a terceirização é uma prática de gestão e organização do trabalho, peça chave do "modelo japonês" (toyotismo), que se autonomizou desse sistema, tornando-se uma modalidade que passa a ser central para fazer valer, no campo do processo de trabalho, a flexibilidade exigida pelo capita- 
lismo contemporâneo, hegemonizado pela lógica financeira e pelas políticas neoliberais. Uma conjuntura em que as empresas buscam garantir seus altos lucros, exigindo dos trabalhadores a maximização do tempo e altas taxas de produtividade, com a redução dos custos do trabalho e a "volatilidade" nas formas ocupacionais e de contratação. Nessa medida, a terceirização é uma estratégia de controle e disciplinamento dos trabalhadores por parte do capital, que os divide, os fragmenta, tornando-os mais heterogêneos, facilitando assim as condições para impor uma maior exploração, através da redução de riscos e custos, por meio da diminuição da remuneração do trabalho, da intensificação das jornadas de trabalho, do aumento dos mecanismos de controle e subordinação direta dos trabalhadores, da negociação privada das condições de trabalho e da redução dos direitos e benefícios conquistados pelos trabalhadores. Juridicamente, se manifesta como uma tática empresarial de exploração do trabalho assalariado e fragmentação da classe operária através da interposição de terceiros na relação de emprego (assalariamento) visando o seu ocultamento, que se vale de novas e velhas formas contratuais atípicas de trabalho, que resulta na erosão do contrato individual de emprego como paradigma de proteção social do trabalho, e afasta a relação de trabalho assalariada da regulamentação pública construída no pós-guerra sob as diretrizes da Orgaస్్ nização Internacional do Trabalho.

กิ $\quad$ Essa concepção de terceirização se situa no plano mais geral das relações entre capital e trabalho e que tem no campo do processo de $\rightarrow$ trabalho, o lugar decisivo e determinante para $\dot{2}$ se compreender a sua centralidade na atual i̛ dinâmica do capitalismo flexível. Entretanto, $\vec{\Delta}$ embora seja uma concepção necessária para tratar dos aspectos conceituais da terceirização, é insuficiente para acompanhar e analisar os processos empíricos em curso na sua diversidade e nas suas implicações. Nessa medida, faz-se necessário buscar mapear como os estudos sobre terceirização no Brasil vêm tratan- do o fenômeno e quais são os elementos que contribuem para um entendimento comum em suas distintas manifestações e nos diferentes segmentos do trabalho e dos trabalhadores.

\section{MAPEANDO OS ESTUDOS EMPÍ- RICOS NO BRASIL: há um conceito operacional de terceirização?}

Os levantamentos realizados no Banco de Teses e Dissertações da Capes ${ }^{1}$ e nos periódicos do Scielo, ${ }^{2}$ no período de 2000 a 2020, para as áreas de Direito, Ciências Sociais, Sociologia, Sociologia e Política, Sociologia e Antropologia, Ciências da Saúde, Ciências Humanas e Ciências Sociais Aplicadas, permitem apresentar um mapeamento das pesquisas realizadas nessas últimas duas décadas. Importante registrar que os primeiros estudos sobre a terceirização datam do início dos anos 1990, como parte do processo de reestruturação produtiva, a adoção generalizada do toyotismo, que tem nas redes de subcontratação (terceirização) uma das principais práticas de gestão. Naquela década, grande parte das pesquisas foi realizada no setor industrial, com destaque para a indústria automotiva, química/petroquímica e petroleira.

No campo jurídico, os primeiros artigos que tratam do fenômeno promoveram uma abertura epistemológica na chamada "doutrina" trabalhista, tendo em vista a necessidade de uma abordagem interdisciplinar para a compreensão do fenômeno e o acompanhamento do seu impacto no direito do trabalho, especialmente da sua dimensão normativa. Ressalta-se a construção reflexiva apresentada por Viana (1999) sobre os novos modos de pro-

\footnotetext{
${ }^{1}$ No Banco de teses e dissertação da Capes foram encontradas 195 dissertações de mestrado e 39 teses de doutorado, nas seguintes áreas selecionadas: Direito (174), Ciências Sociais (30), Sociologia (25), Sociologia e Política (3) e Sociologia e Antropologia (2), de programas de pós-graduação de 61 universidades brasileiras, totalizando 234 trabalhos.

${ }^{2}$ No Scielo, foram encontrados 75 artigos em 15 periódicos das áreas de ciências humanas, sociais aplicadas e ciências da saúde.
} 
duzir e trabalhar, e sobre os vários modos de flexibilizar, no artigo "A proteção social do trabalhador no mundo globalizado: o direito do trabalho no limiar do século XXI". Igualmente aquela promovida por Delgado (2003) na sua obra "Curso de Direito do Trabalho", ao destacar um capítulo exclusivo para o tratamento do tema da terceirização, em um grande esforço teórico e conceitual para identificar o conteúdo sócio-jurídico do fenômeno.

No transcorrer dos anos 2000, outros estudos foram realizados para além da indústria, abarcando o setor de serviços, destacadamente, a terceirização no trabalho bancário. Nestas últimas duas décadas, o crescimento e a difusão da terceirização se deram de forma epidêmica e atingiu áreas nucleares das empresas, sob modalidades e formas jurídica diversas, a exemplo das cooperativas de trabalho, das chamadas "empresas do eu sozinho" (pejotização) ${ }^{3}$ e de algumas formas de trabalho em domicílio, incluindo o teletrabalho (Druck, 2011).

As pesquisas no setor privado abarcaram inúmeras categorias profissionais: além dos bancários, já referidos, call centers, automotivo, petroquímico, petroleiro, mineração, siderurgia, indústria de alumínio, construção civil, confecções, agricultura, comércio, empresas privatizadas de energia elétrica, comunicações; no setor público: empresas públicas, bancos estatais e serviços públicos de saúde e educação.

A terceirização cresceu em todas as direções e de forma destacada no âmbito do setor público e das empresas estatais, o que pode ser explicado pela adoção de políticas neoliberais pelos sucessivos governos e pela implementação da reforma do Estado, cuja regulamentação entrou em vigor no final dos anos 1990, em especial a chamada "publicização" das atividades não exclusivas do Estado, com a transferência de serviços públicos para instituições privadas, através do processo de terceirização,

${ }^{3} \mathrm{O}$ termo tem origem na substituição de empregados por Pessoas Jurídicas, isto é, os trabalhadores são "intimados" pelas empresas contratantes a abrir um registo como empresa e, dessa forma, passam a "prestar serviços", perdendo a condição de empregados e, consequentemente, todos os direitos trabalhistas. que cresceu na sua forma mais tradicional com a contratação de empresas prestadoras de serviços, mas também se ampliou através de outras modalidades: cooperativas, organizações sociais (OSs) organizações da sociedade civil de interesse público (OSCIPs), ONGs, sobretudo na área de saúde.

No âmbito das pesquisas jurídicas realizadas no período, estudos que tomaram a terceirização como objeto de estudo já apontavam os limites que o fenômeno encontrava no ordenamento jurídico trabalhista e suas formas contratuais, apesar do seu histórico déficit de eficácia (Oliveira, 2004). Neste sentido, vale ressaltar o trabalho de Carelli (2003), por situar a terceirização como processo de intermediação de mão-de-obra, desnudando, assim, a vocação do fenômeno em tencionar o paradigma fundante e central do direito do trabalho, qual seja, a contratação direta da força de trabalho subordinada/assalariada.

A riqueza dos estudos empíricos permite desvendar a variedade das formas de terceirização, o amplo leque de categorias profissionais atingindo todos os setores da atividade econômica (indústria, comércio e serviços), nas áreas privada e pública. Da mesma maneira revelam as diversas formas jurídicas que assume, valendo-se de contratações atípicas ou especiais, em contraste com o contrato de trabalho padrão (empregatício), bem como de novas categorias jurídicas que flexibilizam o uso do trabalho assalariado, especialmente seu padrão de remuneração e ajuste dos tempos de trabalho e de descanso.

No que se refere às formas de terceirização identificadas pelas pesquisas, pode-se apresentar a seguinte classificação ou tipologia, que tem como ponto de partida a relação da contratante com quem vai desenvolver o trabalho: as empresas prestadoras de serviços, empresas de trabalho temporário, parcerias, as cooperativas, as ONGs/Entidades Sem Fins Lucrativos, Prestadores de serviço (autônomo)/ firma individual(PJ), Organizações Sociais (OSs) e Organizações da Sociedade Civil de 
Interesse Público (OSCIPs), estas duas últimas utilizadas no serviço público.

O que há em comum entre essas diferentes modalidades ou tipos de terceirização? Em primeiro lugar, o tipo de relação que se estabelece entre a unidade contratante e a contratada, ambas são instituições/unidades/empresas que são reguladas através do direito civil (comercial ou administrativo) e, portanto, não é uma relação submetida ao direito do trabalho. Segundo, todos os que trabalham nessas diferentes modalidades de terceirização são considerados "prestadores de serviços" e, deste modo, não são reconhecidos como trabalhadores pelas contratantes. Terceiro, a relação de trabalho aparece exclusivamente para as contratadas, eximindo as contratantes de responsabilidade sobre o trabalho e os trabalhadores. Todas essas situações contribuem para negar a relação de assalariamento que está encoberta por um "terceiro". Nessa perspectiva, Filgueiras e Cavalcante (2015, p.3), ao criticarem os argumentos da retórica empresarial que associam a terceirização à "especialização", à "focalização" ou à "divisão do trabalho", propõe concebê-la como "o processo de valorização do capital por meio de organização e gestão do trabalho em que não há admissão da relação contratual com os trabalhadores em atividade e que se utiliza, para tanto, de um ente interposto (...)". Na mesma direção, Marcelino e Cavalcante (2012, p.337) se referem "às conনิ sequências jurídicas da terceirização”, quando …..a tomadora, se livra das regras dessa área ᄋे do Direito [do trabalho] - tradicionalmente o mais restritivas, pois protetoras do trabalhador $\stackrel{\text { ? }}{\rightarrow}$ - e passa a administrar contratos com outras - empresas na esfera do Direito Civil”. E ainda க் Dutra e Filgueiras (2021), que entendem a ter-

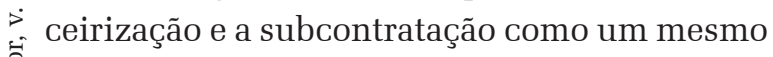
fenômeno cuja essência é a precarização do trabalho e o rebaixamento da limitação da exploração do trabalho que ela provoca enquanto estratégia jurídica de organização e gestão do trabalho. Com base em pesquisas empíricas realizadas, os autores afirmam que, independen- temente da forma jurídica como a terceirização é disposta, a empresa contratante permanece no controle da força de trabalho. Assim entendem a terceirização como "uma estratégia de contratação de pessoal através de um intermediário, que é uma entidade interposta entre um trabalhador e um gestor efetivo do trabalho e da produção" (Dutra e Filgueiras, 2021, p.10). Para os autores, a terceirização tende a reduzir a resistência individual, minar ações coletivas, enfraquecer a eficácia da regulamentação institucional, diminuir os custos e aumentar a produtividade, consistindo na principal estratégia de gestão de mão-de-obra na atual fase do capitalismo.

Em outros termos, o que caracteriza a terceirização e lhe dá um conteúdo comum em suas diferentes modalidades, é a negação por parte do sujeito que a utiliza, da relação de trabalho que ela encerra. Nessa medida, esse "ente interposto" pode ser "formal" (como são as empresas prestadoras de serviços) ou "simulado", como é o caso da pejotização, dos trabalhadores autônomos, das cooperativas e do trabalho a domicílio. Em todas elas, a interposição entre o trabalho realizado e a instituição contratante serve para encobrir uma relação de assalariamento e, desta forma, não se subordinar ao direito do trabalho.

Isto porque, as diversas dimensões desse campo do direito (legislativa, institucional, sindical) estão sob a influência de princípios protetivos, amparados constitucionalmente e por normas internacionais, comprometidos com a irrenunciabilidade de direitos, inalterabilidade unilateral do contrato ou em prejuízo ao trabalhador, irredutibilidade salarial, continuidade do vínculo de trabalho e a primazia da realidade dos fatos na configuração da relação jurídica de emprego. Trata-se de um arranjo princípio lógico e normativo que busca conter o exercício do poder diretivo do contratante, garantir um sistema de proteção ao salário, limitar as jornadas de trabalho e garantir tempos de descanso, fomentando a estabilidade e a segurança no emprego e a proteção à saúde do trabalhador. 
Os campos de análise das pesquisas sobre terceirização são também diversos. É possível identificar como lócus da investigação: o processo e organização do trabalho e, a partir desse espaço, as análises envolvem: o mercado de trabalho, a organização coletiva (os sindicatos), a saúde do trabalhador e os direitos do trabalho. Cabe observar que essas várias dimensões analisadas nas pesquisas são testemunho da natureza multidimensional da terceirização. Vale ainda registrar que os estudos sobre a precarização do trabalho têm apresentado a terceirização como uma das suas principais manifestações e, quando se busca construir uma tipologia ou expor as diferentes faces da precarização, também como fenômeno multidimensional, conforme apresentado por Druck (2011), a terceirização está presente em todas elas: i) nos padrões de gestão e organização do trabalho, com condições extremamente precárias, através da intensificação do trabalho, com baixos salários, extensão da jornada, sustentados na gestão pelo medo, na discriminação e nas formas de abuso de poder através do assédio moral; ii) nas formas de mercantilização da força de trabalho, constituindo um mercado de trabalho heterogêneo, segmentado, com formas de inserção (contratos) precários, sem proteção social e altas taxas de rotatividade; iii) nas condições de (in)segurança e saúde no trabalho - resultado dos padrões de gestão, que desrespeitam o necessário treinamento, as informações sobre riscos, medidas preventivas coletivas, etc. na busca incessante de redução de custos, mesmo que à custa de vidas humanas, levando a altos índices de acidentes de trabalho, adoecimento e mortes; iv) no isolamento, na perda de enraizamento, de vínculos, de inserção, resultantes da descartabilidade, da desvalorização e da discriminação, condições que afetam decisivamente a solidariedade de classe, solapando-a pela brutal concorrência que se desencadeia entre os próprios trabalhadores, dificultando a sua identidade de classe; v) no enfraquecimento da organização sindical e das formas de luta e representação dos trabalhadores, decorrentes da violenta concorrência entre os mesmos, da sua heterogeneidade e divisão, implicando numa pulverização dos sindicatos; vi) na negação do direito do trabalho, impulsionada pelo comportamento patronal, que questiona a sua tradição e existência, expressa na reforma trabalhista de 2017, que liberou a terceirização sem limites, além de outras mudanças na CLT que esvaziaram seu conteúdo protetivo.

Os estudos empíricos se, por um lado, revelam a diversidade dos tipos de terceirização, a partir dos quais, é possível construir um conceito operacional, por outro, em sua imensa maioria, não apresenta um conceito de terceirização. Dentre os artigos que fazem parte da base de dados do Scielo na área de ciências humanas no período de 2000 a 2020, apenas um tinha em seu título e como objetivo central construir um conceito de terceirização (Marcelino e Cavalcante, 2012). Nos demais, não há uma problematização conceitual e quando se referem a algum conceito, em geral, o tomam da versão empresarial, mesmo que para criticá-lo e contrapor os resultados das pesquisas.

Pode-se afirmar que Marcelino e Cavalcante foram os pioneiros em tratar da questão conceitual da terceirização, de forma sistematizada, dialogando com outros autores e concepções, e representam uma referência importante na literatura crítica no campo das ciências sociais. O esforço dos autores para apresentar um conceito e uma classificação que permita identificar o que é terceirização e o que não é, contribui muito para avançar operacionalmente na sua definição. Entretanto, apesar de considerarem uma "definição abrangente", quando a concebem como "...todo processo de contratação de trabalhadores por empresa interposta, cujo objetivo último é a redução de custos com a força de trabalho e/ou a externalização dos conflitos trabalhistas" (Marcelino e Cavalcante, 2012, p.338), de certa forma, restringem o processo de terceirização que tem sido revelado pelas pesquisas empíricas. Ao 
reconhecerem as dificuldades para classificar o que é terceirização, quando afirmam sobre "um hibridismo nas relações entre empresas e trabalhadores, o que torna as fronteiras dos contratos de trabalho, por vezes, pouco claras" (ibidem, p.342), a exemplo de classificar um único trabalhador pejotizado como empresa terceirizada e um autônomo como não terceirizado,“...é quase uma questão puramente formal - o que faz bastante diferença nas consequências legais, mas pouca no que se refere às condições de trabalho" (ibidem, p.342); os autores indicam pistas sobre as limitações de sua proposta. Pois, a partir desse exemplo, o que é comum nesses dois tipos de relação? Um PJ e um trabalhador autônomo? Em ambos a contratante não reconhece a relação de trabalho, não se subordinando ao direito do trabalho, este é o centro da "redução de custos e da externalização dos conflitos trabalhistas", conforme definição do objetivo da terceirização concebido pelos autores.

Portanto, compreender como o fenômeno da terceirização se manifesta no campo jurídico é fundamental uma vez que faz parte da sua essência a negação do modelo de direito do trabalho estruturado na sociedade fordista, especialmente quando entendido como instrumento de resistência dos trabalhadores às formas de controle e exploração do trabalho. E, neste esforço, reconhecer o contrato individual de emprego como categoria central na arquiปี tetura normativa e operacional desse campo s jurídico, como fazem os autores ao apresenta-

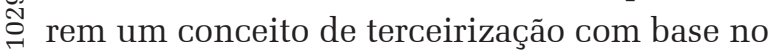
¿ padrão de contratação da força dos trabalhadoจึ res e considerarem a "desvinculação do traba$\dot{2}$ lhador com a empresa que lucra com a venda ङ de produtos ou serviços criados por seu tra-

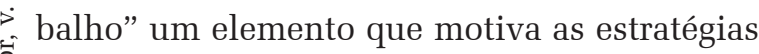
empresariais de gestão da produção e do trabalho (Marcelino e Cavalcante, 2012, p.343).

No caso brasileiro, conforme apresentado por Oliveira (2020), os eixos estruturantes dessa legislação protetora são: (1) a caracterização da relação de emprego como um con- trato especial, bilateralmente estabelecido e que envolve trabalho prestado de forma subordinada, onerosa, pessoal e permanente; (2) a noção de que o risco da atividade econômica (fator que, dentre outros, justifica socialmente o lucro e a mais valia) deve ser assumido pelos empregadores, sendo considerado tempo de serviço o tempo em que o empregado esteja à disposição do contratante, independentemente da execução efetiva do serviço; (3) a presunção de veracidade relativa quanto à manifestação de vontade do trabalhador, dada a sua vulnerabilidade econômica; (4) a indisponibilidade dos direitos trabalhistas como regra, tendo em vista seu caráter social; (5) a proteção contra a despedida indireta, visando a continuidade do vínculo de emprego para a melhoria constante das condições de trabalho; (6) um sistema de proteção ao salário contra a desigualdade e a instabilidade no padrão remuneratório da força de trabalho. Ou seja, um conjunto de medidas que articulam dois momentos distintos da relação contratual: a compra da força de trabalho e o consumo dessa força de trabalho, ou seja, a contratação (nas suas mais diversas modalidades) e a execução do contrato (consumação patronal da força de trabalho, especialmente no tocante à remuneração e à organização da jornada e dos tempos de descanso).

Acontece que esse modelo vem sendo reformado ao longo das últimas três décadas, em um processo contínuo de flexibilização e perda de racionalidade e coerência interna do ordenamento jurídico trabalhista, que deixa de ser capaz de garantir direitos mínimos trabalhistas e servir de horizonte de inclusão social pelo trabalho digno. Uma reconfiguração que, como apontam Artur e Grillo (2020), resultam em grande medida, das disputas em torno da terceirização e que, como ressaltam Viana, Delgado e Amorim (2011), atinge em cheio o contrato de trabalho. 


\section{QUAL É A IMPORTÂNCIA DE UM CONCEITO OPERACIONAL DE TERCEIRIZAÇÃO?}

A necessidade de um conceito operacional atende a duas ordens de naturezas diferentes: uma primeira é o objetivo de medir a terceirização no país. Analisar a sua evolução nos diferentes setores de atividade no tempo e no espaço. Atualmente, os trabalhos que analisam essa evolução quantitativa da terceirização estão limitados pelo tipo de informações das fontes de dados oficiais. ${ }^{4}$ Segundo Pelatieri et al. (2018), as pesquisas domiciliares do IBGE e os registros administrativos do Ministério do Trabalho (extinto pelo atual governo e incorporado ao Ministério da Economia), permitem conhecer alguns aspectos da terceirização, mas há limites e questionamentos sobre as variáveis e seus diferentes usos, resultando em análises distintas sobre o mesmo fenômeno. Vários estudos utilizam a RAIS - Relação Anual de Informações Sociais e a Classificação Nacional de Atividades Econômicas (CNAE), para classificar as "atividades tipicamente terceirizadas" ou atividades-meio, (CUT-DIEESE, 2014; Pelatieri et al, 2018; Krein, 2020). É uma estimativa que indica os números da terceirização apenas dentre os trabalhadores formais e, portanto, exclui uma série de formas de terceirização que estão fora das relações de emprego. Apesar de indicarem as tendências dessa evolução, o que já é extremamente importante, registram apenas parte do fenômeno. No caso da PNAD contínua, embora capte trabalhadores terceirizados em cooperativas e através de empreiteiras que usam trabalho temporário, só consideram a terceirização realizada dentro de uma empresa, o que exclui outras formas de trabalho terceirizado (Marcolino, 2019).

$\mathrm{Na}$ realidade, medir a terceirização é uma dificuldade pela própria natureza do fenômeno, que encobre as relações de trabalho e

${ }^{4}$ Ver Marcolino (2019) que apresenta uma sistematização das perguntas sobre terceirização disponíveis nas principais bases estatísticas sobre o mercado de trabalho no Brasil. cria um manto de invisibilidade dos trabalhadores. Entretanto, é fundamental buscar metodologias que permitam dimensionar a terceirização e, ao se construir um conceito operacional e a sua classificação, também pode permitir comparações nacionais e internacionais.

A segunda ordem é a sua definição para referenciar o tratamento jurídico da terceirização. Seja com o objetivo de coibi-la e no limite, proibi-la, seja na perspectiva de definir uma regulação que minore a sua precarização, e, neste sentido, contribuir para o diálogo entre as pesquisas que buscam dimensionar juridicamente o impacto do fenômeno na sociedade, especialmente na vida dos trabalhadores envolvidos. Isso, no campo jurídico, demanda um olhar cuidadoso sobre a atuação das instituições de regulação do trabalho, sobre a ação coletivas dos trabalhadores na negociação das condições de trabalho. Para tanto, há de partir-se de um conceito operacional capaz de desnudar a relação de exploração que é inerente ao processo de compra e venda do trabalho no modo de produção e organização social capitalista.

\section{CONSTRUINDO UMA METODOLO- GIA "QUALITATIVA" E COMPLE- MENTAR PARA DIMENSIONAR A TERCEIRIZAÇÃO: uma proposta de construção de indicadores ${ }^{5}$}

\footnotetext{
Segundo Januzzi,

Um indicador social é uma medida em geral quantitativa dotada de significado social substantivo, usado para substituir, quantificar ou operacionalizar um conceito social abstrato, de interesse teórico (para pesquisa acadêmica) ou programático (para formulação de políticas). É um recurso metodológico, empiricamente referido, que informa algo sobre um aspecto da realidade social ou sobre mudanças que estão se processando na mesma. Para a pesquisa

${ }^{5}$ Proposta inspirada no projeto de Pesquisa "A Precarização social do Trabalho: uma proposta de construção de indicadores”, 2010, coordenado por Graça Druck e na Dissertação de Mestrado de Adriana Marcolino, "Balanço da produção acadêmica brasileira sobre condições e relações de trabalho dos terceirizados", 2019.
} 
acadêmica, o Indicador Social é, pois, o elo de ligação entre os modelos explicativos da Teoria Social e a evidência empírica dos fenômenos sociais observados (...) (Januzzi, 2003, p.15).

Há um certo consenso na literatura sobre metodologia que a construção de indicadores pode ser com base em estatísticas e fontes secundárias ou de informações quantitativas de estudos de casos e/ou surveys, classificados como indicadores "objetivos" (quantitativos); ou construídos por pesquisa direta e fontes primárias, em geral de cunho qualitativo, com estudos de casos locais, setoriais, regionais, longitudinais, dentre outros, denominados de "subjetivos" (qualitativos).

Entretanto, a perspectiva adotada nessa proposta de indicadores, mesmo reconhecendo as diferenças nas bases de dados que os constituem, afina-se com o entendimento de Besson (1995), que afirma ser toda informação estatística resultado de um trabalho de conceituação, organização e observação e de exploração. Isto significa que por trás dos números, há um modelo conceitual, categorias que são criadas para filtrar a realidade. Portanto, todo dado numérico é quantitativo e qualitativo ao mesmo tempo, compreensão que contribui fortemente para romper com o "fetiche dos números". Do lado da pesquisa qualitativa, com pesquisas diretas, que atentam para singularidades, individualidades e subjetividades, também se pode obter "medidas", números que sinte$\overrightarrow{\mathcal{N}}$ tizam determinadas situações pesquisadas e ‥ que são tão reveladoras como as estatísticas. సิ Em síntese, há uma dupla natureza em ambas abordagens - quantitativistas e qualitativistas $\stackrel{\text { จ }}{\rightarrow}$ - que não são opostas, nem se excluem e, por$\vec{\sim}$ tanto, é preciso trabalhar com as informações में numa perspectiva complementar, combinando $\therefore$ as distintas fontes e naturezas das informações para a produção do conhecimento sobre o fenômeno estudado. das fontes secundárias de dados sobre terceirização já existe um avanço significativo, representado principalmente pelos trabalhos do
DIEESE e de um conjunto de estudiosos que tem buscado "medir" a terceirização e sua evolução no Brasil, (Pelatieri et al, 2018; Krein e Teixeira, 2016; Poschmann, 2008); busca-se propor um caminho complementar, cuja base de dados é constituída por pesquisas realizadas por grupos de pesquisa, por pesquisadores individuais, por dissertações e teses de pós-graduação e outras modalidades acadêmicas de pesquisa; que têm mostrado uma imensa diversidade no tratamento de diferentes objetos e dimensões da terceirização, nos campos das ciências humanas, com destaque para a sociologia do trabalho, direito e economia. São estudos que não são de "fontes oficiais", mas são validados e reconhecidos entre seus pares, no interior do debate acadêmico e que têm mostrado as várias modalidades de terceirização para inúmeros segmentos de trabalhadores (categorias profissionais), nos vários espaços/ campos em que ela se manifesta (processo/local de trabalho; mercado de trabalho, condições de trabalho, saúde do trabalhador, organizações coletiva e sindical, direito do trabalho), com uma diversidade de objetos de estudo, de enfoques, de resultados que permitem construir uma certa generalização, pois cobrem setores, segmentos, regióes, dimensões e especificidades que podem ser sintetizadas em um conjunto de indicadores (Druck, 2010).

De acordo com Marcolino:

\begin{abstract}
Os estudos de caso sobre terceirização têm a relevante capacidade de problematizar o tema e apresentar conclusões sobre esse fenômeno e seus impactos, auxiliando no entendimento de suas características e seus efeitos sobre o mercado e o processo de trabalho, mas, também sobre as relações mais gerais desse processo no local de trabalho com o padrão de acumulação capitalista atual. Entretanto, esses estudos estão dispersos e sua capacidade individual de generalização, por questões de ordem epistemológica e metodológica, é bastante baixa. O que faz sua força é o conjunto (Marcolino, 2019, p.50).
\end{abstract}

A construção desses indicadores, com base nos resultados de pesquisas empíricas realizadas, poderá utilizar como técnica a Revi- 
são Bibliográfica Sistemática (RBS), ou Revisão sistemática da literatura, que tem sua origem nos estudos na área de saúde e vem sendo utilizado em outras áreas do conhecimento, como as ciências sociais. Trata-se de um tipo de investigação que formula uma questão e busca identificar, selecionar, avaliar e sintetizar as evidências relevantes disponíveis em estudos já realizados (Galvão e Pereira, 2014). Segundo Marcolino (2019), a RBS não é simplesmente um levantamento da literatura existente, pois exige a formulação de hipóteses ou questões, a partir das quais se examina estudos e pesquisas publicados, como fontes de informações sobre determinado tema. ${ }^{6}$

Não se trata de apresentar, por ora, no âmbito desse artigo, uma proposta mais acabada da metodologia a ser utilizada, mas a intenção é apenas enunciar e defender a necessidade e possibilidade da construção de indicadores de terceirização, conforme proposto.

Entretanto, há um pré-requisito fundamental para o desenvolvimento dessa proposta: o conceito operacional de terceirização e sua classificação, que demarcarão o escopo do levantamento a ser realizado através da Revisão Bibliográfica Sistemática.

Nesta medida, dialogando com alguns estudiosos já referidos anteriormente, propomos definir a terceirização como: uma forma de gestão e organização do trabalho em que a relação de trabalho (ou de assalariamento) não é reconhecida pelo sujeito que a utiliza, para não se subordinar ao direito do trabalho e, desta forma, obter a almejada redução de custos do trabalho. Para isso, se vale de um "ente interposto" que pode assumir distintas "personalidades": como as empresas prestadoras de serviços, caso mais "formal" de terceirização e por modalidades que "simulam" a condição

${ }^{6}$ Para entender como utilizar a RBS, ver Marcolino (2019) que apresenta detalhadamente o percurso metodológico que desenvolveu, apresentando todas as etapas, desde os critérios para a seleção dos documentos, mapeamento e sistematização das informações e análise. No caso do estudo de Marcolino, em sua pesquisa sobre terceirização no Brasil, ela optou por fontes de dados o Banco de Teses e dissertações da Capes, sem incluir os artigos e livros publicados sobre terceirização. de um terceiro, a exemplo das cooperativas, da pejotização, dos trabalhadores autônomos, dos trabalhadores a domicílio, dentre outras formas encontradas nas pesquisas realizadas.

\section{CONSIDERAÇÕES FINAIS}

Há pelo menos três décadas o campo das ciências sociais tem sido desafiado a compreender a terceirização, seu funcionamento e impacto na sociedade, especialmente para o conjunto dos trabalhadores. Os estudos desenvolvidos nas universidades, institutos de pesquisa e demais espaços de produção de dados e informações na área do trabalho apontam a complexidade do fenômeno, que requer uma abordagem interdisciplinar e rigorosa em termos conceituais e metodológicos.

No Brasil, os estudos sobre terceirização foram capazes de evidenciar sua amplitude e diversidade com respeito a dinâmica que assume nos diversos setores da economia. Eles revelaram seu impacto no mercado de trabalho, no ordenamento jurídico trabalhista e no padrão de atuação coletiva dos trabalhadores e foram capazes de demostrar sua estreita relação com o processo de precarização social do trabalho no país, aprofundando desigualdades nas mais diversas estruturas da sociedade brasileira. No entanto, apesar da riqueza dessa produção científica, o diálogo entre estes estudos ainda requer aproximações conceituais e metodológicas, que permitam análises comparativas e ampliadas do fenômeno.

Este texto buscou lançar luzes para o desafio desta construção coletiva, ao retomar o diálogo sobre o conceito de terceirização e apresentar uma proposta de criação de uma metodologia qualitativa de construção de indicadores, que permitam dimensionar a terceirização a partir dos resultados de pesquisas empíricas desenvolvidas no país.

Recebido para publicação em 05 de julho de 2021 Aceito em 20 de outubro de 2021 


\section{REFERÊNCIAS}

ARAÚJO, Anísio José da Silva. Paradoxos da modernização: terceirização e segurança em uma refinaria de petróleo. 2001. 381p. Tese (Doutorado em Saúde Pública) - Escola Nacional de Saúde Pública Sergio Arouca, Fundação Oswaldo Cruz, Rio de Janeiro.

ARTUR, Karen; GRILLO, Sayonara. Terceirização e arenas de reconfiguração do direito do trabalho no Brasil. Revista Estudos Institucionais, v.6, n.3, p.1184-1213, set./dez.2020.

BESSON, Jean Louis. (Org.) A ilusão das estatísticas. São Paulo: Editorial UNESP, 1995. 289p.

BRAVERMAN, Harry. Trabalho e Capital monopolista - a degradação do trabalho no século XX. Rio de Janeiro: Ed Guanabara, $3^{\mathrm{a}}$ ed., 1987.379p.

CARELLI, Rodrigo de Lacerda. Terceirização e intermediação da mão-de-obra: ruptura do sistema trabalhista, precarização do trabalho e exclusão social. Rio de Janeiro: Renovar, 2003.

CARVALHO, Felipe Estrela Santos. Os frutos da negociação: convenções coletivas de trabalho e a regulação social do emprego rural na fruticultura irrigada do Submédio São Francisco (1994-2012). 2015. Dissertação (Mestrado em Ciências Sociais) - Programa de Pós-Graduação em Ciências Sociais da Universidade Federal da Bahia.

CASTEL, Robert. As metamorfoses da questão social: uma crônica do salário. Rio de Janeiro: Ed. Vozes, 1998. 611p.

CUT-DIEESE. Terceirização e Desenvolvimento: uma conta que não fecha - Dossiê sobre o impacto da terceirização sobre os trabalhadores e propostas para garantir a igualdade de direitos. São Paulo, 2014, 56p. Disponível em: https://www.cut.org.br/system/uploads/ck/files/ Dossie-Terceirizacao-e-Desenvolvimento.pdf. Acesso em: 1.10.2015.

DELGADO, Maurício Godinho. Curso de Direito do Trabalho. São Paulo: LTr, 2003.

DRUCK, Graça. A precarização social do trabalho no Brasil: uma proposta de construção de indicadores. Salvador: CRH/ UFBA/CNPq. Projeto de Pesquisa Bolsa Produtividade do CNPq, 2007/2010 (mimeo).

DRUCK, Graça. Trabalho, Precarização e Resistências: velhos e novos desafios? Caderno CRH, Salvador, v.24, 2011, n. spe 01:35-54.

DUTRA, Renata Queiroz; FILGUEIRAS, Vitor Araújo. A polêmica sobre o conceito de terceirização e sua regulação. Revista Jurídica Trabalho e Desenvolvimento Humano, సิ Campinas, v.4, p.1-31, 2021.

ลิ

FILGUEIRAS, Vitor Araujo; CAVALCANTE, Sávio. 今े Terceirização: um problema conceitual e político.

Disponível em: https://diplomatique.org.br/terceirizacaooิ um-problema-conceitual-e-politico/, 2015. Acesso em: ¿ 10.02.2015

ले

GALVÃO, Taís Freire, PEREIRA, Mauricio Gomes. Revisões sistemáticas da literatura: passos para sua elaboração.

2. Brasília: Epidemiologia e Serviços de Saúde, v.23, n.1, p.183मे 184, 2014.

$>$ HARVEY, David. Condição pós-moderna: uma pesquisa tิ sobre as origens da mudança cultural. São Paulo: Loyola, 5 $5^{\circ}$ ed. 1992. 349p.
JANUZZI, Paulo de Martino. Indicadores Sociais no Brasil - conceitos, fontes de dados e Aplicações. Campinas, SP: Ed. Alínea, 2a ed., 2003. 169p.

KOWARICK, Lúcio. Trabalho e vadiagem: a origem do trabalho livre no Brasil. Rio de Janeiro: Paz e Terra, 1994, $124 \mathrm{p}$.

KREIN, José Dari; TEIXEIRA, Marilane O. Terceirização e relações de trabalho. In: MACAMBIRA JÚNIOR; ARAÚJO, T. P.; LIMA, R. A. (Coord.). Mercado de trabalho: qualificação, emprego e políticas sociais. Fortaleza: IDT, 2016 .

KREIN, José Dari. A reforma trabalhista de 2017: seus impactos no mundo do trabalho. Texto base para o concurso de livre docência Instituto de Economia da UNICAMP, 2020. Mimeo.

MARCELINO, Paula, CAVALCANTE, Sávio. Por uma definição de terceirização. Caderno $C R H$, Salvador, v.25, p. 331-346, 2012.

MARCOLINO, Adriana. Balanço da produção acadêmica brasileira sobre condições e relações de trabalho dos terceirizados. 2019. 253p. Dissertação (Mestrado em Sociologia) - Programa de Pós-Graduação em Sociologia da Universidade de São Paulo.

MELLO, Lawrence Estivalet de. Crise do contrato de trabalho e ilegalidades expandidas. 2020. Tese (Doutorado em Direito) - Universidade Federal do Paraná.

OLIVEIRA, Isabela Fadul. A terceirização e as condições de eficácia da legislação trabalhista no Brasil. 2004. Tese (Doutorado em Direito) - Programa de Pós-Graduação em Direito da Universidade de Sẫo Paulo.

OLIVEIRA, Isabela Fadul. Flexibilização da legislação trabalhista. In: IVO, Anete B. L. (Coord.). Dicionário temático desenvolvimento e questão social: 110 problemas contemporâneos. Brasília: Annablume, 2020, p. 311-318.

PELATIERI, Patricia. et. al. Terceirização e precarização das condições de trabalho: condições de trabalho e remuneração em atividades tipicamente terceirizadas e contratantes. In: CAMPO, A. Terceirização do trabalho no Brasil - novas e distintas perspectivas para o debate. Brasília: IPEA, 2018, p.11-31.

POSCHMANN, Márcio. Superterceirização do trabalho. São Paulo: LTr, 2008.

THÉBAUD-MONY, Annie; DRUCK, Graça. Terceirização: a erosão dos direitos dos trabalhadores na França e no Brasil. In: DRUCK, G.; FRANCO, T. (Org.) A perda da razão social do trabalho: terceirização e precarização. São Paulo: Ed Boitempo, 2007. p.23-58.

VIANA, Márcio Túlio. A proteção social do trabalhador no mundo globalizado: o direito do trabalho no limiar do século XXI. Revista LTr, São Paulo, v.63, n.7, 1999, p.885896.

VIANA, Márcio Túlio; DELGADO, Gabriela Neves; AMORIM, Helder Santos. Terceirização - Aspectos gerais. A última decisão do STF e a Súmula 331 do TST. Novos enfoques. Revista TST, Brasília, v.77, n.1, jan/mar., 2011.

VIOTTI DA COSTA, E. Da Monarquia à República: momentos decisivos. São Paulo: Grijalbo, 1977, 326p. 


\section{THE CONCEPTUAL DEBATE ON OUTSOURCING: an interdisciplinary approach}

\author{
Graça Druck \\ Isabela Fadul de Oliveira
}

The article aims to systematize and discuss the concept of outsourcing in Brazilian research, seeking to create a dialogue between the different disciplinary areas of studies, as well as indicating the different levels of abstraction of the concept. It starts from a broader and more structural definition of the place of outsourcing in contemporary capitalism, discussing the different forms of outsourcing, revealed by empirical studies, in order to, from them, present some operational concepts, especially in the legal field. In addition to the conceptual questioning, a proposal is presented to create a qualitative methodology for the construction of indicators that allow for dimensioning outsourcing, taking as "raw data" the results of empirical research carried out in the country.

KeYwORDS: Outsourcing. Concept. Indicators.

\section{LE DÉBAT CONCEPTUEL SUR L'EXTERNALISATION: une approche interdisciplinaire}

\author{
Graça Druck \\ Isabela Fadul de Oliveira
}

L'article vise à systématiser et discuter le concept d'externalisation dans la recherche brésilienne, en cherchant à créer un dialogue entre les différents domaines d'études disciplinaires, ainsi qu'en indiquant les différents niveaux d'abstraction du concept. Il part d'une définition plus large et plus structurelle de la place de l'externalisation dans le capitalisme contemporain, abordant les différentes formes d'externalisation, révélées par des études empiriques, afin, à partir de celles-ci, de présenter quelques concepts opérationnels, notamment dans le domaine juridique. En plus du questionnement conceptuel, une proposition est présentée pour créer une méthodologie qualitative pour la construction d'indicateurs permettant de dimensionner l'externalisation, en prenant comme "données brutes" les résultats de recherches empiriques menées dans le pays.

Mots-clés: Sous-traitance. Concept. Indicateurs.

\footnotetext{
Graça Druck - Doutora em C. Sociais pela UNICAMP. Professora titular do Programa de Pós-graduação em C. Sociais da Faculdade de Filosofia e C. Humanas e do Programa de Serviço Social da Universidade Federal da Bahia. Pesquisadora do CRH/UFBa. Bolsista Produtividade do CNPq. Membro da REMIR. Integra e lidera o Grupo de Pesquisa Trabalho, Trabalhadores e Reprodução social do Diretório do CNPq. Desenvolve pesquisas ná área de sociologia do trabalho. Publicações recentes: co-organizadora com Jair Batista da Silva do livro Trabalho, Precarização e Resistências, Edufba (2019); co-autora com Luiz Filgueiras do livro O Brasil nas Trevas - (2013 - 2020): do golpe neoliberal ao neofascismo, Boitempo (2020).

Isabela Fadul de Oliveira - Doutora em Direito do Trabalho pela Universidade de São Paulo. Professora do Departamento de Direito Privado da Universidade Federal da Bahia. Integra os grupos de pesquisa "Trabalho, Trabalhadores e Reprodução Social" (CRH-UFBA) e "Transformações do Trabalho, Democracia e Proteção Social” (FD-UFBA), desenvolvendo pesquisas na área de direito do trabalho e educação jurídica. Publicações recentes: Flexibilização da legislação trabalhista. In: IVO, Anete B. L. (Coord.). Dicionário temático desenvolvimento e questão social: 110 problemas contemporâneos. Brasília: Annablume, 2020; Procesos de reforma laboral en Brasil y Argentina: discusiones comparadas en torno a la reglamentación del trabajo assalariado (co-autoria JAVIER, E. P.). In: Edilton Meireles. (Org.). Direito e processo do trabalho: entre reformas, indústria 4.0, negociação e proteção. 1ed.Salvador: Editora Paginæ, 2021, v. 1, p. 689-707; Educação Jurídica no contexto da pandemia de Covid-19: uma experiência de ensino-aprendizagem remota na UFBA (co-autoria SANTANA, Q. S. M.; PEREIRA, S. S.). In: Felipe dos Reis Barroso; Maria Vital da Rocha. (Org.). Educação jurídica híbrida, metodologias ativas e inovação tecnológica. 1ed.Fortaleza: Mucuripe, 2021, v. 1, p. 139-150.
} 
